\title{
Calibration and Evaluation of Aquacrop for Maize (Zea Mays L.) under Different Irrigation and Cultivation Methods
}

\author{
Diaa Fliah Hassan ${ }^{1,2^{*}}$, Alaa Salih Ati', AbdulKhalik Saleh Neima ${ }^{3}$ \\ 1 College of Agricultural Engineering Sciences, University of Baghdad, Baghdad, Iraq \\ 2 Water Resources Engineering College, Al-Qasim Green University, Babylon, Iraq \\ ${ }^{3}$ Ministry of Agriculture, Baghdad, Iraq \\ * Corresponding author's e-mail: diaafliah@wrec.uoqasim.edu.iq
}

\begin{abstract}
Crop models of simulation are utilised effectively to evaluate the management of irrigation strategies which help in managing the water use. The aim of this study was to verify the validity of the Aquacrop model of maize under the surface and sprinkler irrigation systems, and a cultivation system, borders and furrows, and for two varieties of Maze (Fajr and Drakma) at two different sites in Iraq, i.e. the Babylon and Al-Qadisiyah governorates. The current study conducted an experiment to evaluate the Aquacrop model capacity in simulating canopy cover (CC), biomass (B), dry yield, harvest index (HI), and water productivity (WP). The results of RMSE, R2, MAE, d, NSE, $\mathrm{CC}, \mathrm{Pe}$ indicated good results and high compatibility between the measured and simulated values. The highest achieved results were identical to the method of sprinkler irrigation due to the decrease in the amount of water consumed and the furrows cultivation method as the aerial roots were covered and the cultivar was Drakma. The highest values for the statistical data were $\mathrm{R}^{2}$ (90 and 96\%), RMSE (0.60, 0.73), MAE (0.5, 0.67), d (0.97, 0.97), NSE $(0.87,0.90)$, for the Babylon and Al-Qadisiyah sites, respectively. As for the CC values, they were very compatible with the values of $\mathrm{R}^{2}$ and ranged between (92-99)\%. The prediction error was Pe and minor errors were found. Thus, the Aquacrop model can be used reliably to evaluate the effectiveness of proposed irrigation management strategies for maize.
\end{abstract}

Keywords: Aquacrop, sprinkler irrigation, canopy cover, maize

\section{INTRODUCTION}

Water is the limiting factor for agricultural production in many regions of the world that suffer from the scarcity of water resources. There is an increasing interest in its sources in the future as its limitations call for a focus on the optimal use of water. Water management and its proper use represent a priority in arid and semi-arid regions or in the regions with low rainfall. The methods of good management include controlling the amount of water given in each irrigation, the number of irrigations (irrigation scheduling), the ability of the soil to store water, and the need of the plant in its different growth stages to reach the highest productivity (Spellman, 2018).
Maize (Zea mays L.) is a member of the Maydeae family and is a monoecious annual herbaceous plant, the most important of which is the Zea genus, which includes the Maize species (Sahuki, 1990). Globally, Maize is ranked as the first largest crop in terms of production and the second crop after wheat in terms of cultivated area as the total cultivated area with Maize in the whole world in 2008 amounted to nearly 161 million hectares, producing approximately 823 million tons, with an average of 3.5 tons $\mathrm{h}^{-1}$ (FAO, 2009). In the Arab countries, Maize received the second rank after wheat in terms of production and the third one after wheat and barley in terms of cultivated area as the total cultivated area with Maize in the these countries reached 1640.42 thousand 
hectares to produce about 7533.10 thousand tons at a rate of 4.6 tons $^{-1}$ (Arab Organization for Agricultural Development, 2008; Al-Khaled et al., 2008). The crop can be exposed to water stress during the growing season or during specific growth stages that are more tolerant to these stresses. This makes it possible to save irrigation water even though it reduces the yield to a specific degree, which leads to the introduction of additional agricultural areas without the need to provide new sources of water (Merriam, 1995; Soe, 2019). One of the goals of deficit irrigation is to increase the efficiency of water use by eliminating the irrigation that has less impact on the final yield. It can be practiced in the agricultural areas where the water supply is limited, and the unit water cost is high.

As a result, the increased temperature of global warming and changes in climate have major implications for agriculture, affecting ecosystems and the benefits they provide to societies. This increasingly affects crop productivity, agricultural resources of soil, water and food security. Crop models have been used as a decision support tools guide worldwide for many years to analyse and the effects of weather and climate change on the growth and production of the crop. AquaCrop applications are usually utilised in assessing the management system and climate change strategies, more particularly, in drylands as the soil moisture is vital for the growth and production of the crop. According to Kowalik et al. (2014) and Kefale (2018), this model has been widely adopted to cover various purposes such as assessing the growth and production of crops, moisturizing, watering, and transpiration in addition to assessing the effect of climate changes in low moisturized areas.

Crop growth simulation programs and models have advanced along with computer technology since the late 1960s with the aim of supporting simulation of plant physiological processes as well as describing the growth and development of the crop. This development coincided with the efforts exerted to model crop growth by changing the objectives, group of users, or the results of agricultural policies ranging from explanatory models with accurate scientific vision at the paper level to those that focus on scientific applications and the impact of management practices on a single crop or a complex agricultural system (AbiSaab et al., 2015; Andreoli et al., 2000).
This progress has imposed different systems of models regarding the levels of complexity, processes to be addressed, their functions, selection of algorithms, measures of typical growth units, and the quality of inputs required (Bouman et al., 1996; Hammer et al., 2003; Fischer et al., 2014). Sinclaire and Soltani (2012) showed that all crop simulation models agree that they are mathematical representations of the plant growth processes that are affected by the interactions between genotype and factors surrounding the crop, and that the use of crop simulation models can be an effective complement to experimental research, as they are used to understand the response of crops. For potential changes in crop traits, traditional management processes, and climate variables. Smith and Steduto, (2012) showed that in the nucleus of any model of crop growth, there is a set of equations that estimate the rate of biomass production from at least one of the resources that form the main engine for plants to produce biomass, which is either carbon dioxide, solar radiation, or water.

AquaCrop is a program that simulates the interrelationship between plant and soil as the plant extracts water and nutrients from the root zone of the soil. The program takes into account the field management factors (such as soil fertility) and irrigation management, as these factors affect the mutual relationship between plant and soil. The program also takes the relationship with the atmosphere through the upper boundaries of the studied mass where evaporation-transpiration (ETo), carbon dioxide $\left(\mathrm{CO}_{2}\right)$, and the energy needed for plant growth are calculated. The water is discharged from the studied mass through its lower boundaries to the deep soil or underground water reservoir in case the groundwater level is high. Water can ascend to the studied mass with capillary action (FAO, 2017; He et al., 2021).

The investment of arable land is worthless over the long term, if the crop practices are not appropriate, although these arable lands are the principal means in which the farmers invest natural resources, due to the limited availability of both arable land and water and the suitable biophysical constraints to the production of crops, which can reduce crops as a result of a global climate change (IPCC, 2001; Pachauri et al., 2014).

A study of the maize crop was conducted in 2012-2013 at Kashmir institute of Medical Sciences and Technology, titrimetric "volumetric analysis" has been conducted by using the 
climate data in 2012. Root Mean Square Error (RMSE) has been calculated and the result was low, as opposed to the results of the AquaCrop model which yielded good efficiency of (0.99 and 0.71 ). The performance of the AquaCrop model was very satisfactory and very similar to the reality of different seed rates of Zea mays indentata (Raja et al., 2018).

There are many studies about frequency of irrigation of different types of crops in order to increase the productivity of irrigation water by using the Aquacrop model, which was conducted and confirmed by using the experimental data in 20092010, the value of Root Mean Square Error(RMSE) was $15.54 \%$ of biomass (Sandhu et al., 2015).

Another study aimed at improving the irrigation schedule to increase the water use efficiency using the AquaCrop model and the $\beta$ NSGS algorithm. It used four models of climate data models, which are dynamic climate data with and without adaptation, and constant climate data with and without adaptation to maize production in summer. The fourth approach The fourth approach gave the best results when the climatic data were stable for all irrigation methodsdepths of 400, 325 and $200 \mathrm{~mm}$ for a dry, natural and wet year, respectively (Mwiya et al., 2020).

A study was conducted in the Great Southern Plains in the United States in calibrating the AquaCrop model for two sites, after which a study was conducted for the remaining years and the simulation of the canopy cover showed that there was an increase in the yield with an increase in the amount of water (Masasi et al., 2020). In addition, many studies have been conducted on the possibility of using the Aquacrop program in simulating the maize crop by testing the calibration and validity of the model using statistical standards such as (RMSE, R², d, E, MAE), and it was found that the model has a high potential in predicting yield and water characteristics. (Markovic et al., 2020; Abedinpour, 2016; Zhang et al., 2019; Sandhu and Irmak, 2019).

\section{MATERIALS AND METHODS}

\section{Study site}

Two field experiments were carried out to cultivate the Zea mays L., during the 2019 fall agricultural season in two sites with different textures, the first site is loamy soil in one of the fields of the Agriculture Division of Medhatia, Babylon Governorate. The site is located at latitude $\left(44^{\circ} 36^{\prime} 32 . \mathrm{N}\right)$ north and longitude $\left(32^{\circ}\right.$ 28'22.E) east and at an altitude of $28 \mathrm{~m}$ above sea level. The second was an alluvial silty loam soil in one of the fields of Al-Nouriyah Research Station, Ministry of Agriculture located in Al-Nouriyah sub-district, Al-Qadisiyah Governorate. The site is located within latitude $\left(44^{\circ} 47^{\prime} 59 . \mathrm{N}\right)$ north and longitude ( $44^{\circ} 56^{\prime} 31$.E) east and at an altitude of $25 \mathrm{~m}$ above sea level. The field soils were classified as sedimentary levels classified into a level under the great groups Typic Torrifluvent according to the classification (Soil Survey Staff, 2016; Mohammed,2018). Representative soil samples were taken from the soil at two depths of $0-0.30 \mathrm{~m}$ and $0.30-0.60 \mathrm{~m}$. The soil samples were dried by air, then milled and passed through a sieve with a hole diameter of $2 \mathrm{~mm}$, then some physical and chemical characteristics were determined in Tables (1) and (2).

\section{Climate Condition}

The climate of the study sites is classified into arid and semi-arid regions with an average temperature ranging between $(15-49) \mathrm{m}$ and rainfalls (1.7-40) $\mathrm{mm}$ for Babylon governorate, as well as an average temperature (15-52 m) and rainy intermediate (0.1-35) $\mathrm{mm}$ for Al-Qadisiyah governorate, as shown in (Figure 27). The two governorates are witnessing a significant decrease in the rates of rainfall during the agricultural season, which coincides with the hottest months in central and southern Iraq, as the heat begins in the month of May-November. (Figures 1 and 2) also show the monthly average of rainfall and wind speed rates for the two study sites for the year 2019 .

\section{Agriculture practice}

The experiment was carried out on a plot of 2,500 square meters of $57 \mathrm{~m} * 44 \mathrm{~m}$ in both study sites (Babylon Governorate and Al-Qadisiyah Governorate). The land was plowed with a moldboard plows at multiple times. The laser adjustment operations were performed. The cultivation was done by checking the distance from one plant to another $0.75 \mathrm{~m}$ after the plant reached approximately $20 \mathrm{~cm}$. The field was divided into three plots. The experiment was carried out with 
Table 1. Some physical properties of field soil before planting.

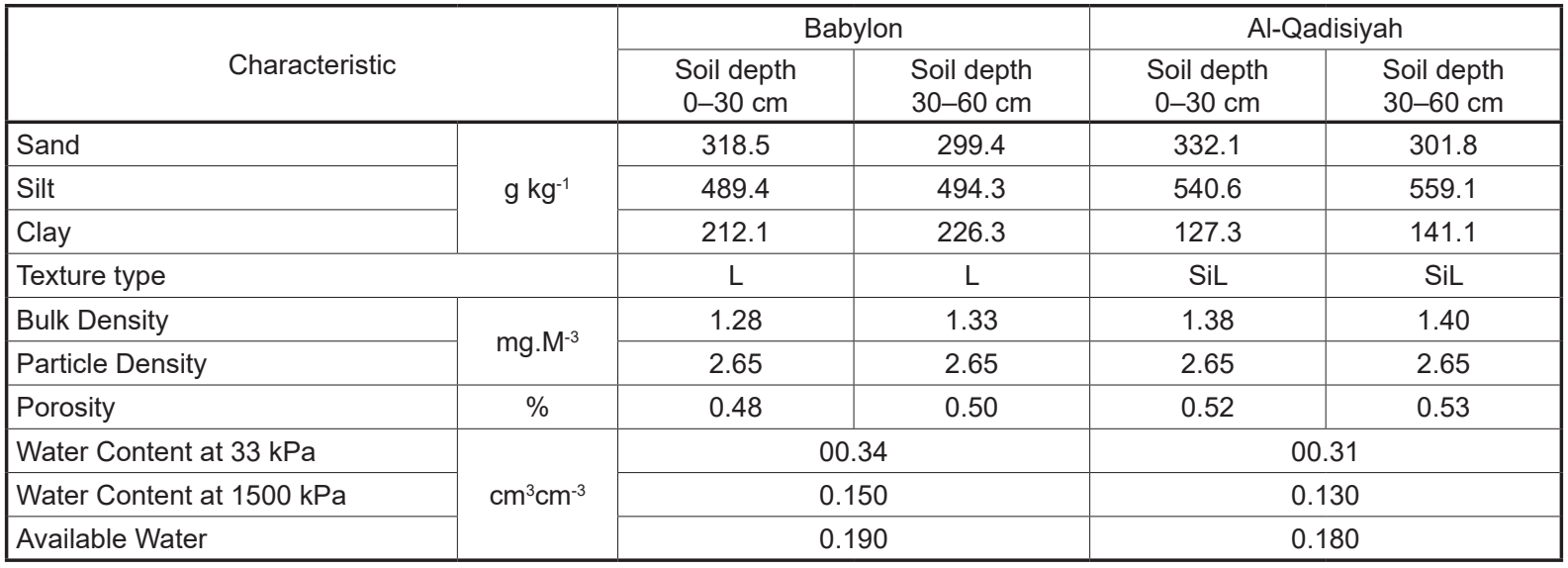

panels of dimensions $7.5 \mathrm{~m} \mathrm{x} 9 \mathrm{~m}$. The field was divided into experimental units and with three replications, leaving a separation distance of $5 \mathrm{~m}$ between the two irrigation methods, a distance of $4 \mathrm{~m}$ between varieties, $1 \mathrm{~m}$ between the experimental units, and $2 \mathrm{~m}$ between plots for surface irrigation. It was lesser than for sprinkler irrigation for the purpose of controlling irrigation and pipelining operations.

The conducted treatments were:

\section{Statistical Comparison}

In this study, five statistical parameters were applied to test the performance of the model and compare the simulated and measured results:

1. Root mean square error (RMSE) (Jacovides and Kontoyiannis, 1995):

$$
\text { RMSE }=\sqrt{\frac{1}{n} \sum_{i=1}^{n}(S i-M i)^{2}}
$$

where: $\mathrm{Si}$ and $\mathrm{Mi}$ are simulated and measured values, respectively, and $\mathrm{n}$ is the number of observations.

2. Determination Coefficient $\left(\mathrm{R}^{2}\right)$ (Moksony and Heged, 1990):

$$
\mathrm{R}^{2}=\frac{\sum \mathrm{Si} \mathrm{Mi}-\sum \mathrm{Si}+\sum \mathrm{Mi}}{\sqrt{\sum \mathrm{Si}^{2}-\left(\sum \mathrm{Si}\right)^{2} \mathrm{x}} \sqrt{\sum \mathrm{Mi}^{2}-\left(\sum \mathrm{Mi}\right)^{2}}}
$$

3. Mean Absolute error (MAE) (Jacovides and Kontoyiannis, 1995):

$$
\mathrm{MAE}=\frac{1}{\mathrm{n}} \sum_{\mathrm{i}=1}^{\mathrm{n}}|\mathrm{mi}-\mathrm{si}|
$$

4. Index of agreement (d) of (Willmott, 1982):

$$
\mathrm{d}=1-\frac{\sum_{\mathrm{i}=1}^{\mathrm{n}}(\mathrm{Si}-\mathrm{Mi})^{2}}{\sum_{\mathrm{i}=1}^{\mathrm{n}}(\mathrm{Si}-\overline{\mathrm{M}}|+\mathrm{Mi}-\overline{\mathrm{M}}|)^{2}}
$$

\begin{tabular}{|c|c|c|c|c|c|}
\hline \multirow{2}{*}{\multicolumn{2}{|c|}{ Characteristic }} & \multicolumn{2}{|c|}{ Babylon } & \multicolumn{2}{|c|}{ Al-Qadisiyah } \\
\hline & & \multirow{2}{*}{$\begin{array}{c}\text { Soil depth } \\
0-30 \mathrm{~cm}\end{array}$} & \multirow{2}{*}{$\begin{array}{c}\text { Soil depth } \\
30-60 \mathrm{~cm} \\
2.0\end{array}$} & \multirow{2}{*}{$\begin{array}{c}\text { Soil depth } \\
0-30 \mathrm{~cm} \\
2.3\end{array}$} & \multirow{2}{*}{$\begin{array}{c}\text { Soil depth } \\
30-60 \mathrm{~cm} \\
3.7\end{array}$} \\
\hline $\mathrm{ECe}$ & ds $\mathrm{m}^{-1}$ & & & & \\
\hline \multicolumn{2}{|c|}{$\mathrm{pH}$} & 7.45 & 7.38 & 7.55 & 7.50 \\
\hline Organic Matter & $\mathrm{g} \mathrm{kg}^{-1}$ & 10.7 & 8.2 & 8.8 & 6.3 \\
\hline $\mathrm{CaCO} 3$ & $\mathrm{~g} \mathrm{~kg}^{-1}$ & 298 & 263 & 278 & 252 \\
\hline CaSO4 & $\mathrm{g} \mathrm{kg}^{-1}$ & 12 & 15 & 28 & 32 \\
\hline Available N & $\mathrm{mg} \mathrm{kg}^{-1}$ soil & 38.1 & 37.9 & 36.6 & 32.5 \\
\hline Available $p$ & $\mathrm{mg} \mathrm{kg}^{-1}$ soil & 15.5 & 13.8 & 14.1 & 13.0 \\
\hline Available $\mathrm{k}$ & $\mathrm{mg} \mathrm{kg}^{-1}$ soil & 190 & 178 & 165 & 150 \\
\hline
\end{tabular}

where: $\bar{M}$ is the mean of the $n$ measured values. The value of $d$ range from $-\infty$ to 1.0 .

Table 2. Some chemical properties of field soil before planting 
5. Coefficient of Efficiency (E) (Hanushek, 1974):

$$
\mathrm{E}=1-\frac{\sum_{\mathrm{i}=1}^{\mathrm{n}}(\mathrm{Si}-\mathrm{Mi})^{2}}{\sum_{\mathrm{i}=1}^{\mathrm{n}}(\mathrm{Mi}-\overline{\mathrm{M}})^{2}}
$$

6. Prediction errors (PE)

$$
\mathrm{pe}=\frac{(\mathrm{si}-\mathrm{oi})}{\mathrm{oi}} * 100
$$

where: si and oi are simulated and measured values, respectively

\section{Canopy cover}

The leaf evolution is expressed in the AquaCrop Model program using vegetation instead of the leaf area index (LAI), as the formula proposed by Heng et al. (2009) was used.

$$
\mathrm{CC}=1.005 *\left(1-[\mathrm{EXP}]^{(-0.60 * \mathrm{LAI})}\right)^{1.2}
$$

\section{RESULT AND DISCUSSION}

\section{Canopy cover}

Leaf evolution is expressed in the AquaCrop program using the Canopy cover (CC) rather than the leaf area index (LAI). Canopy cover (CC) is the portion of the soil surface that is covered by vegetation. It ranges from a value of 0 when sowing seeds with $0 \%$ of the soil surface covered and a maximum value at mid-season, which can reach up to a value of 1 in the event that full Canopy cover is reached $(100 \%$ of the soil surface is covered). Through the daily calculation of soil moisture, AquaCrop tracks the stresses that can occur in the root zone, which may affect leaf growth and consequently the development of vegetation. If these stresses are severe, they can cause yellowing of plant leaves.

An accurate estimation of this variable is necessary for the model to produce good or acceptable estimates that reflect both ETa and Biomass as well as the outcome in the current study. A CC
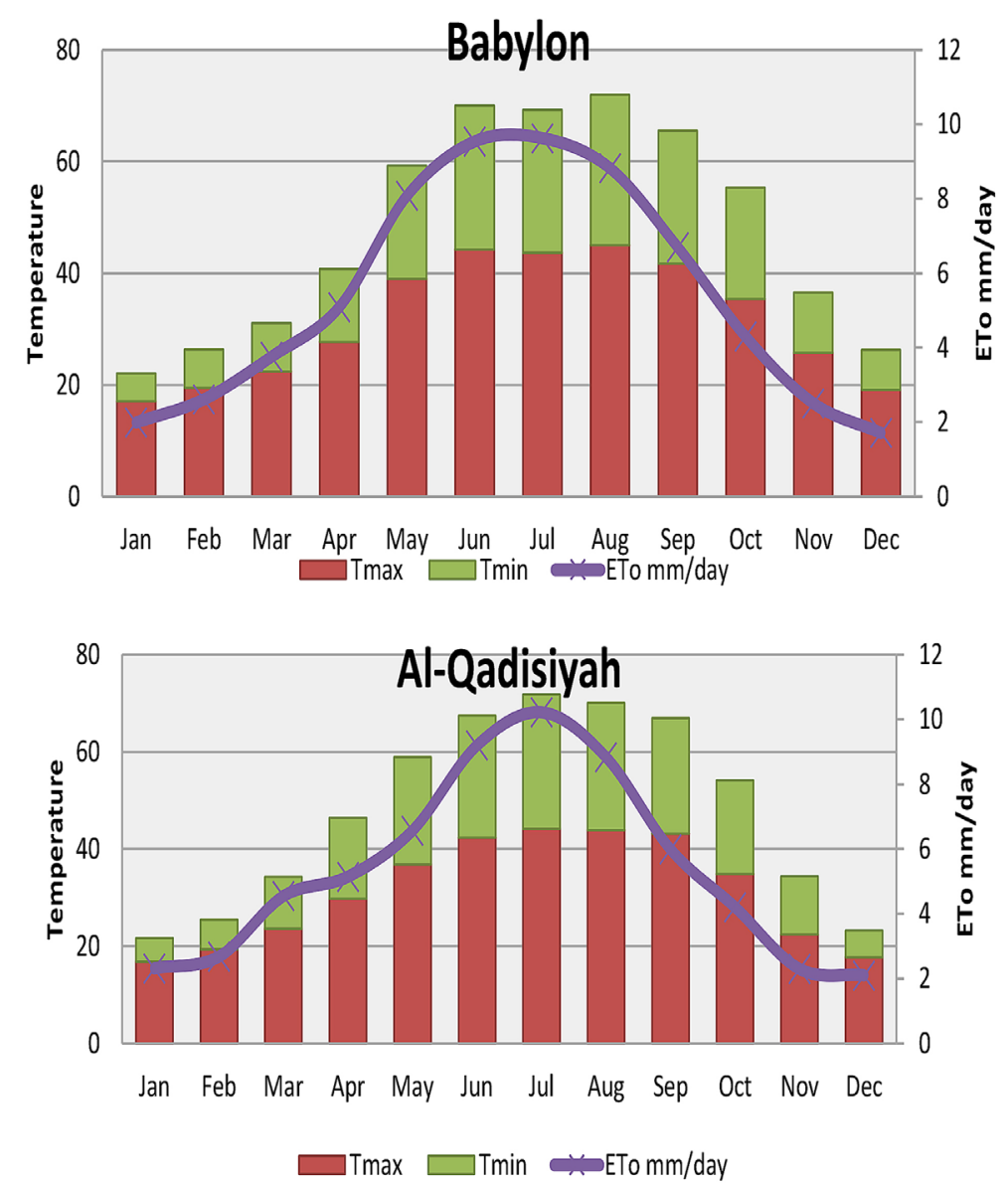

Figure 1. Distribution of temperature and evapotranspiration for the 2019 study year 

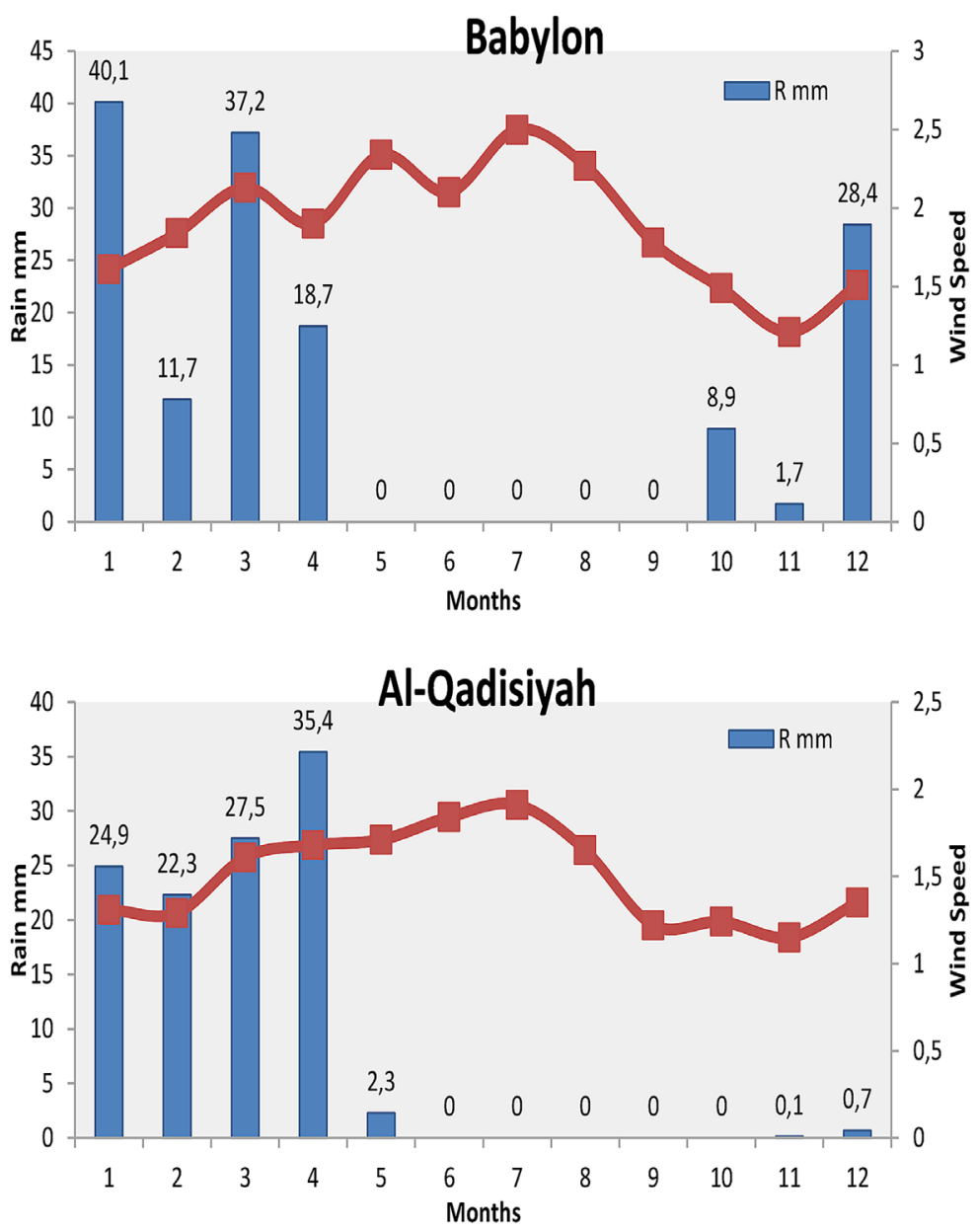

Figure 2. The distribution of rain and wind speed for the year 2019

indicator that was compared between the measured values and the Aquacrop model simulation values was used for the irrigation parameters. The results of the simulated $\mathrm{CC}$ and measured $\mathrm{CC}$ values, shown in Figures (3-A and 3-B) indicated a good agreement between them. It was found that the RMSE values ranged between (2.16-6.27) for the two treatments L1S2BV1 and L1S2FV2, respectively, for the Babylon Governorate. In turn, it ranged between (2.16-3.24) for the L2S2BV1 and L2S1BV1 parameters, respectively, for the Al-Qadisiyah Governorate. The $\mathrm{R}^{2}$ values ranged between (0.929-0.996) for the L1S2FV2 and L1S2BV1 parameters, respectively, for the Babylon Governorate. In contrast, the $\mathrm{R}^{2}$ values were between (0.984-0.996) for the Al-Qadisiyah Governorate for the L2S2FV2 and L2S1BV1 parameters, respectively. The compatibility $\mathrm{d}$ between the simulated and field values was also measured as ranging between (0.979-0.997) for the L1S2FV2 and L1S2FV1 parameters, while it ranged between (0.994-0.998) for the L2S1BV2 and L2S2BV1 parameters for the Babylon and Al-Qadisiyah governorates, respectively.

In order to identify the E efficiency of the program in its simulation of Canopy cover, it was found that the $\mathrm{E}$ values ranged between (0.910.989) for the two L1S2FV2 and L1S2BV1 parameters for the Babylon Governorate, while the E values ranged between $(0.975-0.99)$ for the two parameters L2S1BV2 and L2S2BV1 for the Al-Qadisiyah Governorate. The MAE values for the Babylon governorate were between (2-4.33) for the two parameters L1S2BV1 and L1S2FV2, respectively, while MAE for the the Al-Qadisiyah governorate ranged between (1.66-2.83) for the L2S2BV1 and L2S1BV1 parameters, respectively.

One of the reasons for the compatibility is that the phenology of maize responds well to different climatic conditions. Among the factors influencing a great deal is the temperature, solar brightness and growth period, so the inputs of the vegetation must be adjusted to suit the growing 

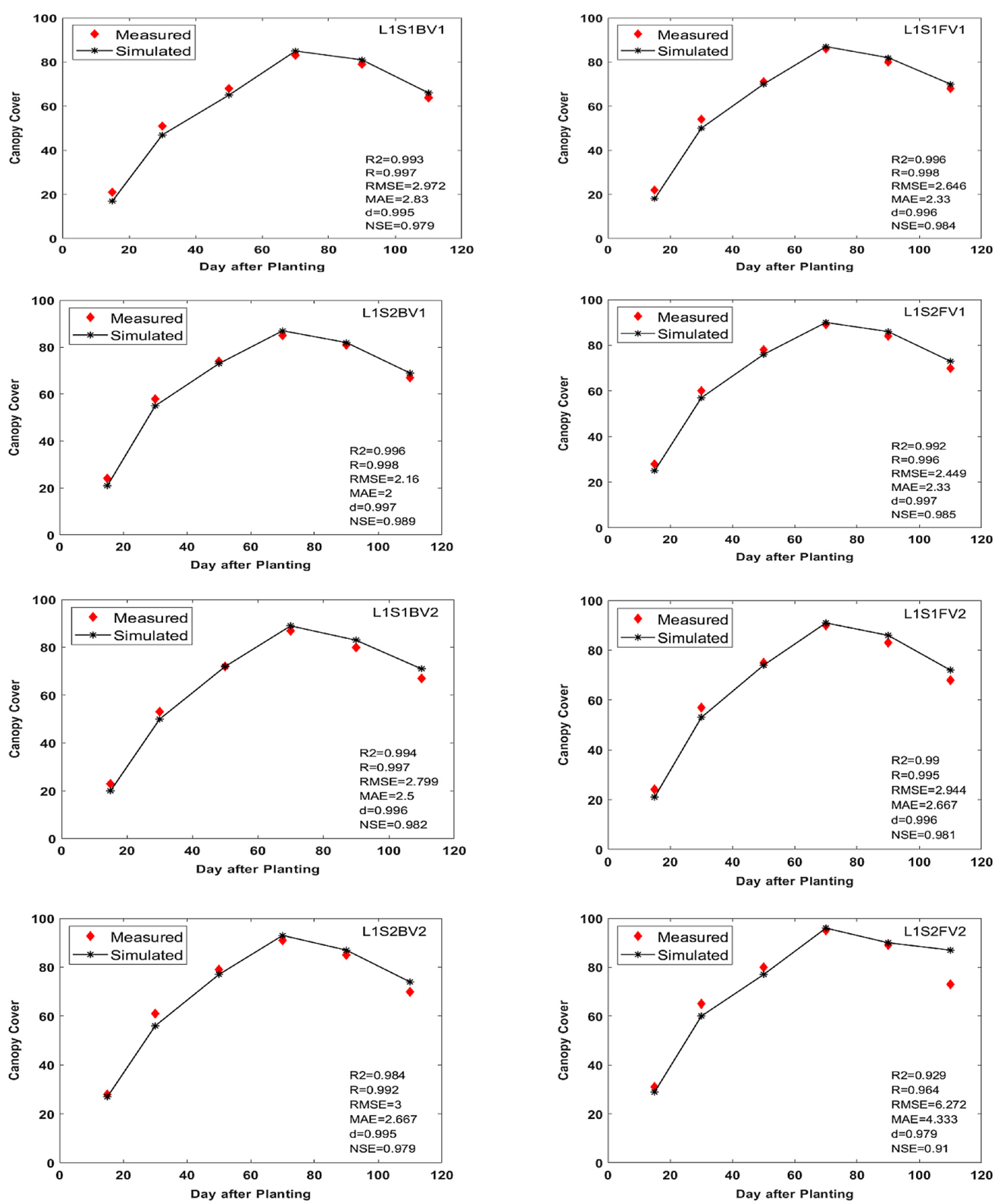

Figure 3. Simulated and measured canopy cover (CC) for all treatments in Babylon

environment (Liu and Xie, 2013 ; Jaafar et al., 2021 and Zwain et al., 2021).

The canopy cover was measured and simulated for different periods of time $(15,30,50,70$, 90, and 110) days, and it was found in general that there was an increase for all parameters of the values of with the passage of time until it reached its highest at 70 days, which is the stage of flowering and then decreased at 90 and 110 days. So is the case for the values simulated by the Aquacrop model. The highest values of canopy cover at 70 days ranged between (83-95) for the L1S1BV1 and L1S2FV2 parameters, respectively, for the Babylon Governorate, while the values were between (80-91) for the L2S1BV1 and L2SFV2 parameters. The reason for the high values of the canopy is due to the increase in the absorption of nutrients when the aerial roots were covered and 
Table 3. AquaCrop calibrated values for main parameters used in maize simulation.

\begin{tabular}{|l|c|}
\hline \multicolumn{1}{|c|}{ Values } & Calibrated \\
\hline Canopy cover per seedling (cm ${ }^{2}$ plant $^{-1}$ ) & 6.7 \\
\hline "Maximum rooting depth (m)" & 0.60 \\
\hline Crop cofficient for transpiration (Kcb) & 1.30 \\
\hline "Canopy expansion stress coefficient (Pupper)" & 0.13 \\
\hline Canopy expansion stress coefficient (Plower) & 0.68 \\
\hline “Canopy expansion curve shape" & 2.5 \\
\hline Stomatal conductance threshold (Pupper) & 0.33 \\
\hline "Stomatal closure shape factor" & 5 \\
\hline Canopy senescence stress coefficient (Pupper) & 0.41 \\
\hline "Canopy senescence shape factor" & 2.5 \\
\hline Aeration stress coefficient (\% vol saturation) & 4 \\
\hline "Canopy decline coefficient (\% GDD-1)" & 0.69 \\
\hline Reference harvest index (\%) & 52 \\
\hline "Crop growth stages (GDD)" & 1800 \\
\hline Time from sowing to emergence & 90 \\
\hline “Time from sowing to max canopy cover" & 760 \\
\hline Time from sowing to senescence & 1720 \\
\hline "Time from sowing to maturity" & 1835 \\
\hline Time from sowing to flowering & 910 \\
\hline "Length of flowering stage" & 193 \\
\hline
\end{tabular}

thus helped to increase the growth and the canopy (Vanuytrecht et al., 2014 ; Jin et al., 2020)

\section{Calibration and Validation}

The capacity of the AquaCrop model was assessed through using statistical parameters which are RMSE, MAE, R2, E, and d. The results are presented for biomass, dry yield, harvest index and water productivity, and their results are shown in Tables 4 and 5.
In order to assess the efficiency of the model in simulating biomass, shown in Table (4), it was found that the Aquacrop model was able to excellently simulate the productivity as the values of the determination coefficient $\left(\mathrm{R}^{2}\right)$ were $(0.90)$ for the two sites, while the RMSE values ( 0.56 and 0.62 ) for the two sites were close to Babylon and Al-Qadisiyah, respectively. The concordance was also high between the true values and the predicted values according to Willmott et al. (1982), as it reached (0.96 and 0.93) for the Babylon and AlQadisiyah sites, respectively. The absolute value errors were (0.46 and 0.55) for the Babylon and Al-Qadisiyah governorates, respectively. The efficiency of using the model was (0.87 and 0.80$)$ for the Babylon and Al-Qadisiyah governorates, respectively. The results were similar to simulating the Aquacrop biomass of maize, confirming that the program performed well in the simulation with respect to the difference in the environment, irrigation method and agriculture (Sandhu and Irmak,2019; Chibarabada et al, 2020).

The results of the calibration showed that the simulated maize yield ranged between (18.41923.53) ton.ha ${ }^{-1}$ in the Babylon Governorate, while it ranged between (15.56-20.68) ton.ha ${ }^{-1}$ in the Al-Qadisiyah governorate. The simulated values reached between (19.38-23.42) ton.ha ${ }^{-1}$ for the Babylon Governorate and (16.41-19.98) ton.ha ${ }^{-1}$ for the Al-Qadisiyah governorate, which is an ideal match under the different conditions of the two fields of the experiment.

Through the other studied factors (water productivity, harvest index, dry yield), it can be ascertained that there is a good agreement between

Table 4. Measured and simulated values for the experiment (Babylon Location)

\begin{tabular}{|c|c|c|c|c|c|c|c|c|}
\hline \multirow{2}{*}{ Parameters } & \multicolumn{2}{|c|}{ Biomass } & \multicolumn{2}{|c|}{ Dry yeild } & \multicolumn{2}{|c|}{ Harvest index } & \multicolumn{2}{|c|}{ Water prodectivity } \\
\hline & Measured & Simulation & Measured & Simulation & Measured & Simulation & Measured & Simulation \\
\hline L1S1BV1 & 18.44 & 19.38 & 11.22 & 11.44 & 44.58 & 45 & 1.22 & 1.29 \\
\hline L1S1FV1 & 20.73 & 19.89 & 11.44 & 11.84 & 44.8 & 46 & 1.49 & 1.27 \\
\hline L1S2BV1 & 19.85 & 20.52 & 10.81 & 11.22 & 45.54 & 46 & 1.62 & 1.62 \\
\hline L1S2FV1 & 22.63 & 22.69 & 12.53 & 12.5 & 44.62 & 45 & 1.75 & 1.71 \\
\hline L1S1BV2 & 19.18 & 19.76 & 10.44 & 10.63 & 45.59 & 46 & 1.3 & 1.46 \\
\hline L1S1FV2 & 21.03 & 21.22 & 11.32 & 11.28 & 46.19 & 46 & 1.56 & 1.53 \\
\hline L1S2BV2 & 20.43 & 20.73 & 10.39 & 10.73 & 49.17 & 50 & 1.8 & 1.85 \\
\hline L1S2FV2 & 23.53 & 23.42 & 12.04 & 11.47 & 48.84 & 49 & 1.99 & 2.2 \\
\hline R2 & \multicolumn{2}{|c|}{0.9} & \multicolumn{2}{|c|}{0.82} & \multicolumn{2}{|c|}{0.95} & \multicolumn{2}{|c|}{0.82} \\
\hline RMSE & \multicolumn{2}{|c|}{0.56} & \multicolumn{2}{|c|}{0.32} & \multicolumn{2}{|c|}{0.6} & \multicolumn{2}{|c|}{0.12} \\
\hline MAE & \multicolumn{2}{|c|}{0.46} & \multicolumn{2}{|c|}{0.27} & \multicolumn{2}{|c|}{0.5} & \multicolumn{2}{|c|}{0.09} \\
\hline D & \multicolumn{2}{|c|}{0.96} & \multicolumn{2}{|c|}{0.93} & \multicolumn{2}{|c|}{0.97} & \multicolumn{2}{|c|}{0.94} \\
\hline NSE & \multicolumn{2}{|c|}{0.87} & \multicolumn{2}{|c|}{0.78} & \multicolumn{2}{|c|}{0.87} & \multicolumn{2}{|c|}{0.72} \\
\hline
\end{tabular}


the measured factors and the simulation. It was found that the determination coefficient $\mathrm{R}^{2}$ was $(0.82,0.95,0.82)$ and $(0.96,0.92,0.74)$ for the dry yield, harvest index and water productivity for Babylon and Al-Qadisiyah, respectively. The RMSE values were $(0.32,0.60,0.12)$ and $(0.08$, $0.73,0.20)$ for the dry matter, harvest index and
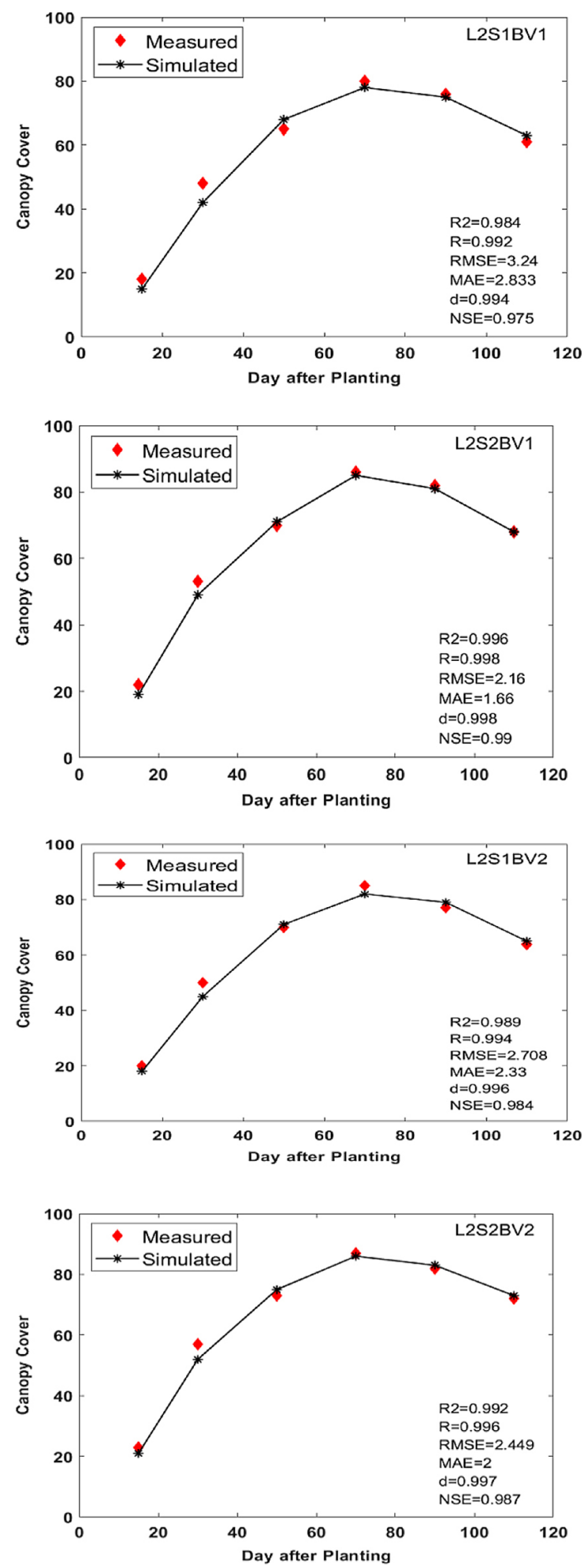

water productivity for the Babylon and Al-Qadisiyah governorates, respectively. In turn, the MAE values were $(0.27,0.50,0.09)$ and $(0.15,0.67$, 0.09 ) for the dry matter, harvest index and water productivity for the Babylon and Al-Qadisiyah governorates, respectively. The values of the index of agreement between the measured and
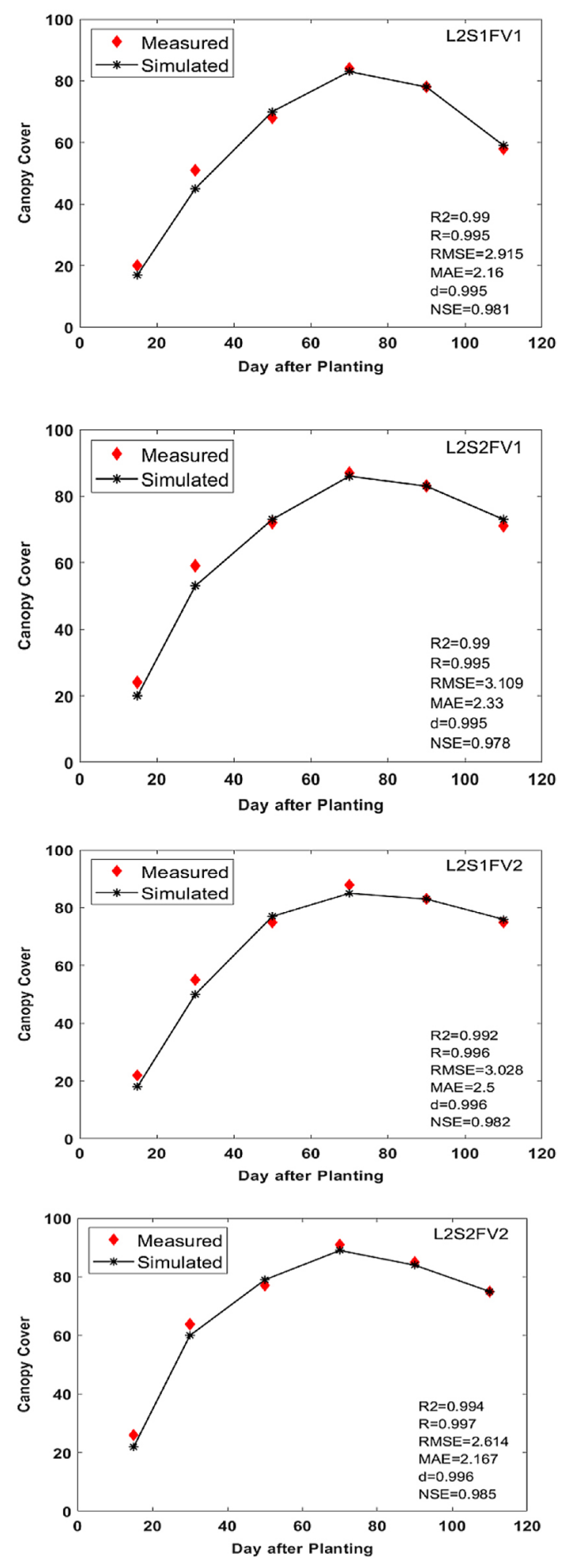

Figure 4. Simulated and measured canopy cover (CC) for all treatments in Al-Qadisiyah 
simulated values d were $(93,94.97) \%$ and $(87$, $97,95) \%$ for dry matter, harvest index, and water productivity for Babylon and Al-Qadisiyah, respectively.

As for the dry yield, the measured values ranged between 10.39-12.53 ton.ha ${ }^{-1}$ for the Babylon Governorate, while it ranged between (10.21-11.21) ton.ha ${ }^{-1}$ in the Al Diwaniyah governorate. The simulated values amounted to between 10.63-12.53 ton.ha ${ }^{-1}$ for the Babylon Governorate and 10.36-11.25 ton.ha ${ }^{-1}$ for the AlQadisiyah governorate. It is an ideal match under the different conditions of the two test fields. As for the harvest index, its measured value was between $44.58-49.17 \%$ for the Babylon Governorate, while it ranged between $38.65-46.62 \%$ in the Al Diwaniyah Governorate. The simulated values reached between $45-50 \%$ for the Babylon Governorate and 39-46\% for the Al-Qadisiyah Governorate. As for water productivity, its measured values reached between (1.22-1.99) for the Babylon Governorate, while it ranged between (1.03-1.56) in the Al Diwaniyah governorate. The simulated values ranged between (1.27-2.2) for the Babylon Governorate and (1.09-1.72) for the Al-Qadisiyah Governorate.

The predictions of the AquaCrop model for grain yield, biomass, and water yield were consistent with the observed data supporting the values of $E$ and $R^{2}$ close to one. The histogram of the evaluated model and the observed values for all treatments related to grain yield, biomass and water productivity are shown in Tables 4 and 5 .

It was found from the foregoing that the best treatment for estimating the value of biomass, dry weight, harvest index and water productivity of maize crop when L1S2FV2 was treated and for the two sites, as the use of $S_{2}$ sprinkler irrigation with furrows irrigation treatment resulted in the values of the estimated calibrations resulting in providing irrigation water at the effective root depth of the plant. The addition of covering aerial roots with irrigation water helped in preparing and providing nutrients near the root system, which gave the best values for the biomass, dry weight, harvest index and water productivity for the two sites.

Sandhu and Irmak (2019) found that the measured dry yield values ranged between (13.9611.98) and (13.07-6.72) and simulated values (14.04-11.36) and (12.72-8.21) hectares $^{-1}$ for the 2011 and 2012 seasons, respectively. The measured values of water productivity were
(2.33-2.81) and (2.64-1.66) and the simulated values were (3.02-2.32) and (2.56-1.92) $\mathrm{kgm}^{-3}$ for the 2011 and 2012 seasons, respectively. The values of the measures of difference were (R2, RMSE, EF) $(0.84,0.36$ and 0.81$)$ and $(0.72,0.83$ and 0.66$)$ for the dry yield and the water productivity values were $(0.10,0.32$ and -4.51$)$ and $(0.30,0.25$ and 0.0$)$ for the 2011 and 2012 seasons, respectively. These results agree with Masasi et al., 2020 and Zhu et al., 2021.

Several tests were also carried out using AquaCrop in the field of simulating irrigation and crop yield response to different water stress applications across large areas of the world (Araya et al., 2021). Greaves and Wang (2016) evaluated the irrigation management strategies for improving agricultural water use in southern Taiwan. Pawar et al. (2017) used AquaCrop to improve water productivity for different irrigation strategies in India.

The ability of the AquaCrop model to simulate yields in response to water has been demonstrated by several researchers, for example Heng et al. (2009), Araya et al. (2010), Andarzian et al. (2011), Stricevic et al. (2011), and Abedinpour et al. (2012). The use of these models can help evaluate and reduce costly and time-intensive field testing (Whisler et al., 1986 ; Ali et al., 2021).

\section{The Prediction error for study}

Table (6) shows the prediction error for biomass, dry matter, harvest index, and water productivity. The results obtained the best calibration of the AquaCrop model using the criterion of prediction error. It ranged between $(0.21 \%)$ as a minimum with the treatment of sprinkler irrigation using the passage irrigation method for the hippocampal variety in the Babylon Governorate, compared to the highest value, which amounted to $5.69 \%$, for the treatment of plate runoff irrigation for this local variety with respect to biomass. The prediction error reached its lowest amount which amounted to $0.17 \%$ for the treatment of flood irrigation by using the method of plate cultivation for the local variety.

When calculating the prediction error of the harvest index, it was found that it ranged between $0.41 \%$ for the wet irrigation treatment of the furrows for the hybrid variety, while the highest value was reached for the furrow flooding irrigation treatment for the local variety. 
As for the water productivity, the values of prediction error ranged between $1.53 \%$ for treating the Al-Qadisiyah site and irrigation by spraying for the local variety. The highest value amounted to $14.07 \%$ for the Babylon Governorate site, irrigation by spraying and furrows for the hybrid variety. The remaining parameters ranged in their values between the above-mentioned values.

The prediction error values obtained to evaluate the values of the AquaCrop model, and the plant and water characteristics shown above found that the model compared to the statistical criteria that were used in its evaluation gave very good values.

The model inputs for the years of the study for irrigation methods, cultivation methods, and adding varying maize types are suitable for verifying the validity of the AquaCrop model, and there is a possibility of replicating this model in the future by investing in climatic data and linking the model to predict the yield of maize in the future (Abendinpour et al., 2012; Paredes and Torres 2017; Giménez,2019; Hassan et al.2021)

\section{CONCLUSIONS}

In this study, an experiment was conducted to investigate canopy cover, biomass, dry yield, harvest index and water productivity, by studying the vegetation crop that was simulated using the Aquacrop program to demonstrate the validity of the simulations of the mentioned characteristics under different irrigation and cultivation systems and for two varieties of corn yield. The main conclusion is as follows (i) The results showed that the Aquacrop program could simulate Canopy Cover, biomass, dry yield, harvest index and water productivity from simulation using the Aquacrop program, and it was found that the best coefficients during the values of the determination coefficient $\mathrm{R}^{2}$ are the treatment of L1S2FV2 (0.929) for $\mathrm{CC}$, while the biomass reached $\mathrm{R}^{2}(0.90)$ and the $\mathrm{R}^{2}$ values were $(0.82,0.95$ and 0.96$)$ for dry yield, harvest index and water productivity, respectively. (ii) The results of this investigation demonstrated that AquaCrop is capable of simulating maize responses to varied irrigated conditions. Additionally, this study showed that utilising irrigation techniques can increase Maize biomass and water productivity. The parameters that are developed in the current research need further investigations to evaluate their validity under other environmental conditions.

\section{REFERENCES}

1. Abedinpour M., Sarangi A., Rajput T.B.S., Singh M., Pathak H., Ahmad T. 2012. Performance evaluation of AquaCrop model for maize crop in a semiarid environment. Agricultural Water Management, 110, 55-66.

2. Abi Saab M.T., Todorovic M., Albrizio R. 2015. Comparing AquaCrop and CropSyst models in simulating barley growth and yield under different water and nitrogen regimes. Does calibration year influence the performance of crop growth models? Agricultural water management, 147, 21-33.

3. Ali Z.A., Hassan D.F., Mohammed R.J. 2021. Effect of irrigation level and nitrogen fertilizer on water consumption and faba bean growth. In IOP Conference Series: Earth and Environmental Science, IOP Publishing, 722(1), 012043.

4. Al-Khaled, Abdel-Hamid, Bakour F., Hajj A., AlAhmad S. 2008. Genetic behavior of some quantitative and qualitative traits in semi-cyclic hybridization in maize. Journal of Agriculture, Biotechnology and Chemical. Mansoura University, 1.

5. Andarzian B., Bannayan M., Steduto P., Mazraeh H., Barati M.E., Barati M.A., Rahnama A. 2011. Validation and testing of the AquaCrop model under full and deficit irrigated wheat production in Iran. Agric.Water Manag., 100, 1-8.

6. Andreoli M., Tellarini V., Antrop M., Armstrong A., Aslam T., Choudhary M.A., Seligman N. G. 2000. Abernethy, VJ, see Downie, IS et al. Adam, N., see Sinclair, TR et al. Adamsen, FJ, see Sinclair, TR et al. Adesina A.A., Mbila D., Nkamleu G.B., Endamana D. Agriculture, Ecosystems and Environment, 81(235), 241.

7. Arab Organization for Agricultural Development. 2008. The League of Arab States. The Agricultural Statistics in the Arab World - Annual Book of Agricultural Statistics.

8. Araya A., Habtu S., Hadgu K.M., Kebede A., Dejene T. 2010. Test of AquaCrop model in simulating biomass and yield of water deficient and irrigated barley (Hordeum vulgare). Agricultural Water Management, 97(11), 1838-1846.

9. Araya A., Prasad P.V.V., Ciampitti I.A., Jha P.K. 2021. Using crop simulation model to evaluate influence of water management practices and multiple cropping systems on crop yields: A case study for Ethiopian highlands. Field Crops Research, 260, 108004.

10. Bouman B.A.M., Van Keulen H., Van Laar H.H., Rabbinge R. 1996. The 'School of de Wit'crop growth simulation models: a pedigree and historical overview. Agricultural systems, 52(2-3), 171-198.

11. Chibarabada T.P., Modi A.T., Mabhaudhi T. 2020. Calibration and evaluation of aquacrop for 
groundnut (Arachis hypogaea) under water deficit conditions. Agricultural and Forest Meteorology, 281, 107850.

12. FAO 2009. ETo Calculator, Land and Water Digital Media Series. Rome, 36.

13. FAO. 2017. Training manual Using AcquaCrop model to evaluate the impact Of climate change on crop production. The Arab Center for the Studies of Arid Zones and Dry Lands (ACSAD).

14. Fischer R.A., Byerlee D., Edmeades G. 2014. Crop yields and global food security. ACIAR: Canberra, ACT, 8-11.

15. Giménez L. 2019. Aquacrop Model Evaluation in Maize Under Different Water Availabilities in the Western of Uruguay. International Journal of Plant, Animal and Environmental Sciences, 9(2), 103-117.

16. Greaves G.E., Wang Y.M. 2016. Assessment of FAO AquaCrop model for simulating maize growth and productivity under deficit irrigation in a tropical environment. Water, 8(12), 557.

17. Hammer G.L., Kropff M.J., Sinclair T.R., Porter J.R. 2002. Future contributions of crop modelling-from heuristics and supporting decision making to understanding genetic regulation and aiding crop improvement. European Journal of Agronomy, 18(12), 15-31.

18. Hanushek E.A. 1974. Efficient estimators for regressing regression coefficients. The American Statistician, 28(2), 66-67.

19. Hassan D.F., Jafaar A.A., Mohamm R.J. 2019. Effect of irrigation water salinity and tillage systems on some physical soil properties. Iraqi Journal of Agricultural Sciences, 50, 42-47.

20. He Q., Li S., Hu D., Wang Y., Cong X. 2021. Performance assessment of the AquaCrop model for filmmulched maize with full drip irrigation in Northwest China. Irrigation Science, 39(2), 277-292.

21. Heng L.K., Hsiao T., Evett S., Howell T., Steduto P. 2009. Validating the FAO AquaCrop model for irrigated and water deficient field maize. Agronomy journal, 101(3), 488-498.

22. IPCC (Intergovernmental Panel on Climate Change), 2001. The Third Assessment Report (TAR): Climate Change 2001 The Scientific Basis. Cambridge University Press for the Intergovernmental Panel on Climate Change.

23. Jaafer A.A., Mohammed R.J., Hassan D.F. 2021. Studying The Thermodynamic Parameters For The Evaluation Of Potassium Availability By Adding Organic Matter.

24. Jacovides C.P., Kontoyiannis H. 1995. Statistical procedures for the evaluation of evapotranspiration computing models. Agric Water Manage, 27, 365-371.

25. Jin X., Li Z., Feng H., Ren Z., Li S. 2020. Estimation of maize yield by assimilating biomass and canopy cover derived from hyperspectral data into the AquaCrop model. Agricultural Water Management, 227, 105846.

26. Kefale, Berhane A., Kefale D. 2018. Applications of Aqua crop Model for Improved Field Management Strategies and Climate Change Impact Assessment: A Review. Modern Concepts \& Developments in Agronomy, 3(2).

27. Kowalik W., Dabrowska-Zielinska K., Meroni M., Raczka T.U., de Wit A. 2014. Yield estimation using SPOT-VEGETATION products: A case study of wheat in European countries. International Journal of Applied Earth Observation and Geoinformation, 32, 228-239.

28. Masasi B., Taghvaeian S., Gowda P.H., Marek G., Boman R. 2020. Validation and application of AquaCrop for irrigated cotton in the Southern Great Plains of US. Irrigation Science, 38(5), 593-607.

29. Merriam J.L. 1995. Amangement control concept for determining the economical frequency of irrigation. ASAE. Annual Meeting. Baper, 65(206), 1-10.

30. Mohammed R.J. 2018. The spatial variability of some chemical properties of gypsiferous soils by using GIS. International Journal of Agricultural and Statistical Sciences, 14(1), 303-312.

31. Moksony F. \& Heged R. 1990. Small is beautiful. The use and interpretation of R2 in social research. Szociológiai Szemle, 130-138.

32. Mwiya R.M., Zhang Z., Zheng C., Wang C. 2020. Comparison of Approaches for Irrigation Scheduling Using AquaCrop and NSGA-III Models under Climate Uncertainty. Sustainability, 12(18), 7694.

33. Pachauri R.K., Allen M.R., Barros V.R., Broome J., Cramer W., Christ R., van Ypserle J.P. 2014. Climate change 2014: synthesis report. Contribution of Working Groups I, II and III to the fifth assessment report of the Intergovernmental Panel on Climate Change Ipcc, 151.

34. Paredes P., Torres M.O. 2017. Parameterization of AquaCrop model for vining pea biomass and yield predictions and assessing impacts of irrigation strategies considering various sowing dates. Irrig. Sci. $35,27-41$.

35. Pawar G.S., Kale M.U., Lokhande J.N. 2017. Response of AquaCrop Model to Different Irrigation Schedules for Irrigated Cabbage.Agric. Res., 6, 73-81.

36. Pragna G., Kumar G.M., Shankar M.S. 2016. Assessment of Cabbage yield under different discharge rate using Aquacrop Model. Progressive Research - An International Journal, 11, 3921-3924

37. Raja, Waseem, Raihana H.K., Purshotum S. 2018. Validating the AquaCrop model for maize under different sowing dates. Water Policy, 20(4), 826-840. 
38. Sahuki, Medhat M. 1990. Maize Production and Improvement. Ministry of Higher Education and Scientific Research. Baghdad University.

39. Sandhu R. \& Irmak S. 2019. Assessment of AquaCrop model in simulating maize canopy cover, soilwater, evapotranspiration, yield, and water productivity for different planting dates and densities under irrigated and rainfed conditions. Agricultural Water Management, 224, 105753.

40. Sandhu S.S., Mahal S.S., Kaur P. 2015. Calibration, validation and application of AquaCrop model in irrigation scheduling for rice under northwest India. Journal of Applied and Natural Science, 7(2), 691-699.

41. Service, Washington, DC, EEUU, 372.

42. Sinclair T.R. \& Seligman N.A. 2000. Criteria for publishing papers on crop modeling. Field Crops Research, 68(3), 165-172.

43. Smith M. \& Steduto P. 2012. Yield response to water: the original FAO water production function. FAO Irrigation and Drainage Paper, (66), 6-13.

44. SOE T. 2019. EFFECT OF IRRIGATION METHODS ON GRAIN MAIZE (Zea mays L.) PRODUCTION (Doctoral dissertation, Yezin Agricultural University).

45. Soil Survey Staff. 2016. Keys to soil taxonomy. USDA, Natural Resources Conservation.

46. Spellman F.R. 2018. The science of water: concepts and applications. CRC press.

47. Stricevic R., Cosic M., Djurovic N., Pejic B., Maksi-movic L. 2011. Assessment of the FAO AquaCrop model in the simulation of rainfed and supplementally irrigated maize, sugar beet and sunflower. Agric. Water Manag., 98, 1615-1621.

48. Vanuytrecht E., Raes D., Steduto P., Hsiao T.C., Fereres E., Heng L.K., Moreno P.M. 2014. AquaCrop: FAO's crop water productivity and yield response model. Environmental Modelling \& Software, 62, 351-360.

49. Wandjie B.B., Lenouo A., Monkam D. 2020. Impact of potential evapotranspiration on maize yields in Northern Cameroon using AquaCrop model. International Journal of Hydrology Science and Technology, 10(1), 17-37.

50. Willmott C.J. 1982. Some comments on the evaluation of model performance. Bull. Am. Meteor. Soc. $63,1309-1313$.

51. Zhang Y., Guo J., Sun B., Fang H., Zhu D., Wang H. 2019. Modeling and dynamic-simulating the water distribution of a fixed spray-plate sprinkler on a lateral-move sprinkler irrigation system. Water, 11(11), 2296.

52. Zhao Y., Li F., Jiang R. 2021. Irrigation schedule optimization based on the combination of an economic irrigation quota and the AquaCrop model. Irrigation and Drainage.

53. Zhu X., Xu K., Liu Y., Guo R., Chen L. 2021. Assessing the vulnerability and risk of maize to drought in China based on the AquaCrop model. Agricultural Systems, 189, 103040.

54. Zwain H.M., Almurshedi K.R., Vakili M., Dahlan I., Naje A.S. 2021. Water Quality and Radionuclides Content Assessment of the Al-Najaf Sea: Case Study. Journal of Ecological Engineering, 22(2) 